\title{
Perencanaan Terminal Khusus Penumpang Umrah Bandara Internasional Juanda
}

\author{
Wajdino Arfa Rajawidad dan Ervina Ahyudanari \\ Departemen Teknik Sipil, Institut Teknologi Sepuluh Nopember (ITS) \\ e-mail:ervina@ce.its.ac.id
}

\begin{abstract}
Abstrak-Dengan jumlah penduduk Kota Surabaya yang sebanyak 2.499.467 jiwa adalah pemeluk agama islam, dan terus meningkatnya pertumbuhan angka ekonomi Jawa Timur. Semakin meningkat pula kemampuan daya beli masyarakat Jawa Timur dalam melaksanakan ibadah umrah. Selama ini untuk penerbangan umrah masih menggunakan Terminal 1 Bandar Udara Internasional Juanda yang pada fungsi awalnya Terminal 1 diperuntukkan operasional penerbangan domestik, meskipun ada beberapa penerbangan internasional di Terminal 1 Bandar Udara Internasional Juanda, namun untuk memenuhi jumlah penumpang umrah fasilitas - fasilitas yang sudah ada terbilang cukup kurang dalam melayani banyaknya jumlah penumpang umrah. Untuk menjawab permasalahan ini diperlukan perencanaan terminal terkait fasilitas - fasilitas yang diperlukan untuk menunjang penumpang umrah. Dalam tugas akhir ini dilakukan 2 perencanaan, yang pertama adalah perencanaan hanya menggunakan peak hour penumpang umrah, yang kedua adalah menambahkan peak hour penumpang domestik pada perhitungan namun hanya pada fasilitas yang bersinggungan. Hasil perhitungan pada tugas akhir ini menunjukkan luas terminal khusus penumpang pada skenario 1 adalah 16090,135 $\mathrm{m}^{2}$ sedangkan pada skenario 2 adalah $16357,135 \mathrm{~m}^{2}$. Hasil perhitungan nilai LOS menunjukkan bahwa fasilitas seperti hall keberangkatan, ruang tunggu keberangkatan, dan hall kedatangan sudah memenuhi kriteria nilai LOS berdasarkan IATA dengan skor A/B (Overdesign). Sedangkan untuk fasilitas passport area pada emigrasi maupun imigrasi masih dibawah standar nilai LOS dengan skor D/E (Subdesign). Evaluasi pada nilai LOS dilakukan pada fasilitas yang masih dibawah standar nilai LOS, maka luasan standar menggunakan skor minimum yaitu skor C (Optimum). Langkah terakhir adalah mendesain layout terminal khusus umrah di terminal 1 Bandar Udara internasional Juanda.
\end{abstract}

Kata Kunci-Terminal Penumpang, Umrah, Bandara, Bandara Internasional Juanda, LOS.

\section{PENDAHULUAN}

$\mathrm{K}^{\mathrm{on}}$ OTA Surabaya menjadi pusat kegiatan ekonomi, keuangan, dan bisnis di daerah Jawa Timur dan sekitarnya. Ekonomi Jawa Timur Tahun 2017 tumbuh 5,45 persen. Dari sisi produksi, pertumbuhan didorong oleh semua lapangan usaha. Kondisi perekonomian yang membaik menjadi salah satu faktor yang mendorong pertumbuhan jumlah penumpang.

Trend peningkatan angka ekonomi Jawa timur juga diiringi dengan tingginya jumlah warga provinsi Jawa Timur sebanyak 42.030 .633 (2017) jiwa dan sebanyak 40.720 .467 (2016) jiwa diantaranya memeluk agama Islam. Kota Surabaya adalah kota di Jawa Timur yang tertinggi jumlah penduduknya yang
Tabel 1.

Pedestrian Walkway Level of Service

\begin{tabular}{ccc}
\hline \hline LOS & Pedestrian Space $\left(\mathrm{m}^{2} / \mathrm{p}\right)$ & Flow Rate $(\mathrm{p} / \mathrm{min} / \mathrm{m})$ \\
\hline A & $>5,6$ & $\leq 16$ \\
B & $3,7-5,6$ & $16-23$ \\
C & $2,2-3,7$ & $23-33$ \\
D & $1,4-2,2$ & $33-49$ \\
E & $0,75-1,4$ & $49-75$ \\
F & $\leq 0,75$ & varies \\
\hline
\end{tabular}

memeluk agama Islam sebanyak 2.499.116 jiwa [1]. Pertumbuhan ekonomi Jawa Timur juga semakin meningkatkan animo penduduk Jawa Timur terutama Kota Surabaya untuk melaksanakan ibadah umrah.

Menurut Kementerian Haji dan Umrah Arab Saudi, jumlah visa umrah yang telah dikeluarkan untuk Indonesia pada 2016 mencapai 699,6 ribu jamaah, meningkat 7,2 persen dari tahun sebelumnya. Angka ini menjadikan Indonesia sebagai negara dengan jumlah jamaah umrah terbesar ketiga di dunia.

Jadwal penerbangan umrah bisa mencapai tiga kali dalam satu minggu [2], sementara di Surabaya sendiri ada 48 biro perjalanan haji dan umrah [3]. Hal ini menunjukkan frekuensi yang cukup tinggi. Keberangkatan umrah biasanya dilakukan dengan rombongan, artinya pada jadwal keberangkatan terminal harus mampu melayani sejumlah orang yang datang secara bersamaan. Kebutuhan para jamaah umrah juga berbeda dari penumpang penerbangan komersial biasa. Fasilitas yang diperlukan oleh para jamaah umrah diantaranya toilet, tempat wudhu, area sholat berjamaah karena kegiatan ibadah juga memiliki waktu tertentu semisal sholat. Kebutuhan fasilitasfasilitas tersebut juga perlu memperhatikan kedatangan jamaah umrah di terminal keberangkatan.

Dengan permasalahan yang ada diatas, maka perlu adanya perencanaan terminal bandar udara khusus umrah pada Terminal 1 Bandar Udara Internasional Juanda. Hal yang meliputi fasilitas terminal bandar udara khusus umrah berupa drop zone, security gate, check in counter, ruang tunggu keberangkatan, dan fasilitas-fasilitas lainnya yang representatif. Pedestrian Walkway Level of Service pada Tabel 1.

Untuk itu perlu adanya suatu desain terminal yang dirancang khusus untuk melayani kebutuhan jamaah umrah.

\section{TINJAUAN PUSTAKA}

\section{A. Standar Fasilitas Terminal Keberangkatan}

Metode perhitungan kebutuhan fasilitas terminal keberangkatan ditentukan sesuai dengan persyaratan teknis 
dari kebutuhan ruang pada fasilitas-fasilitas sisi darat mengacu pada standar IATA [4] sebagai berikut:
Development Reference Manual (ADRM) [7] ada pembedaan ruang untuk berdiri atau duduk penumpang. Digunakan untuk

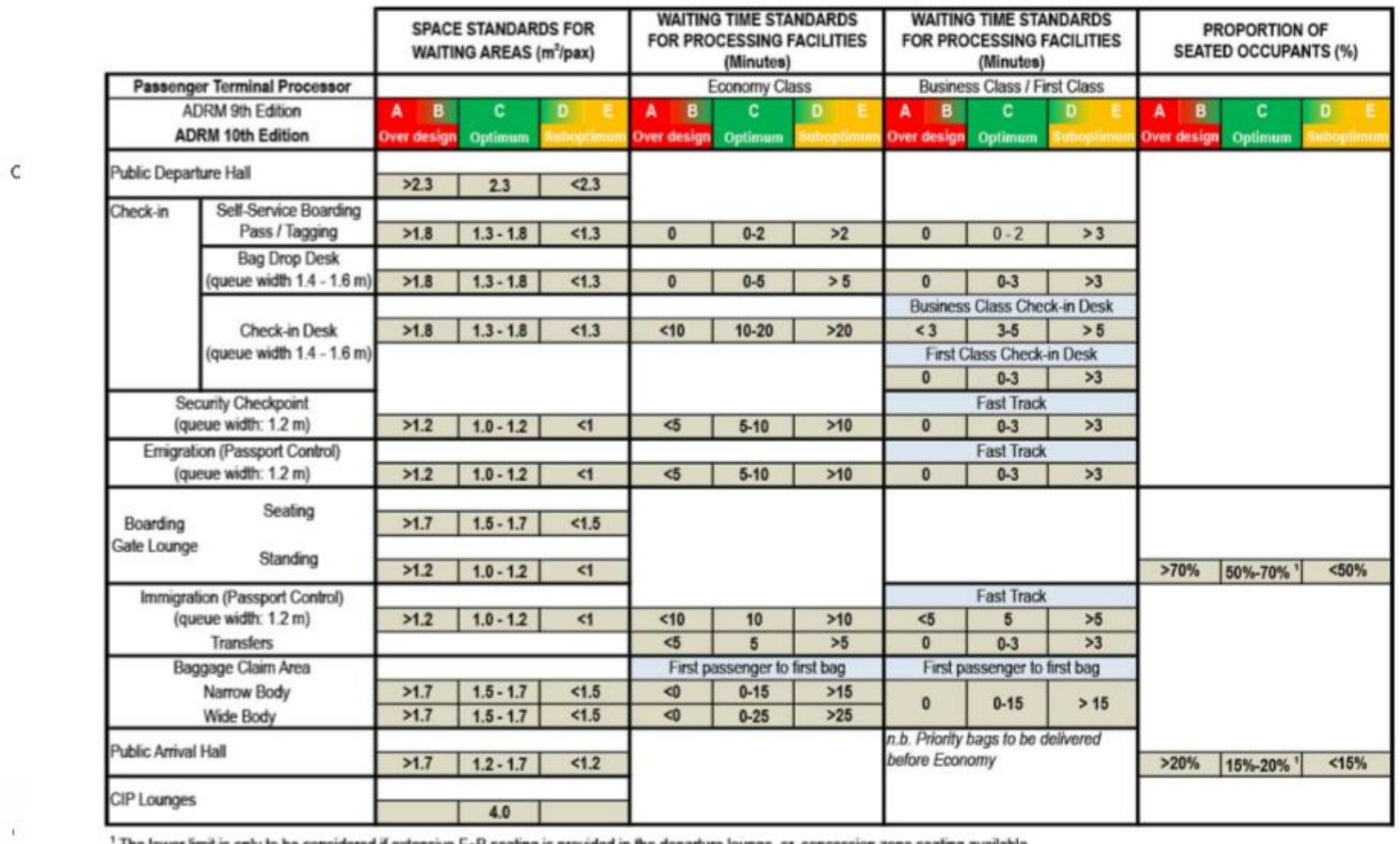

Source: IATA

Gambar 1. Alur Level of Service Penumpang.

1. Kerb Keberangkatan

2. Hall Keberangkatan

3. Security Gate

4. Ruang Tunggu Keberangkatan

5. Check-in Area

6. Check-in Counter

7. Custom Immigration Quarantine

\section{B. Standar Fasilitas Terminal Kedatangan}

Metode perhitungan kebutuhan fasilitas terminal kedatangan ditentukan sesuai dengan persyaratan teknis dari kebutuhan ruang pada fasilitas-fasilitas sisi darat mengacu pada standar IATA sebagai berikut:
1. Baggage Claim Area
2. Custom Immigration Quarantine
3. Hall Kedatangan

\section{Fasilitas Khusus Penumpang Umrah}

Metode perhitungan kebutuhan fasilitas khusus penumpang umrah dilakukan dengan pendekatan perhitungan fasilitas yang mendekati, kebutuhan fasilitas penumpang umrah antara lain.

1. Tempat Sholat

2. Tempat Wudhu

3. Toilet

\section{Teori Level of Service}

Berdasarkan ketentuan IATA dalam dalam Airport ukuran tingkta pelayanan jasa (Level of Service). Pelayanan terbagi dalam beberapa tingkat, (dapat dilihat pada Gambar 1) Teori Level of Service Ruang Sirkulasi

Transportation Research Board (TRB) dalam Highway Capacity Manual mengeluarkan standar level of service untuk pejalan kaki yang sedang berjalan, mengantri, maupun sedang menunggu. Tabel 2. dan Gambar 2. merupakan standar dan ilustrasi level of service untuk pejalan kaki.

\section{E. Metode Forecasting}

Menurut Horenjeff dan McKelvey dalam bukunya, tipe peramalan dan kesulitannya bergantung pada tujuan dari peramalan itu sendiri. Dalam tugas akhir ini dilakukan forecasting hingga 5 tahun ke depan degan tipe time series.

\section{METODOLOGI}

\section{A. Pendahuluan dan Pengumpulan Data}

Identifikasi masalah untuk menentukan rumusan masalah. Masalah yang teridentifikasi adalah perlu adanya peengembangan fasilitas bagi penumpang umrah pada terminal 1) Bandar Udara Internasional Juanda.

Pengumpulan data primer dan sekunder. Data primer adalah waktu menunggu dan pemrosesan pada check-in counter dan custom immigration quarantine. Data sekunder berupa jumlah penumpang umrah melalui Bandara Juanda dan layout eksisting Terminal 1 Bandara Juanda 


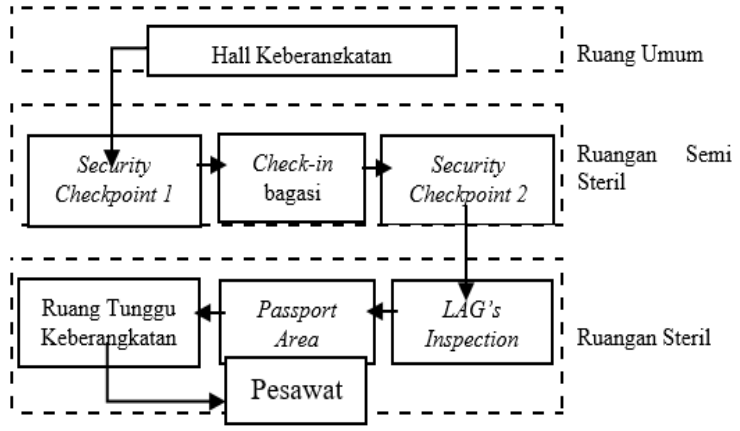

Gambar 2. Alur Keberangkatan Penumpang Umrah

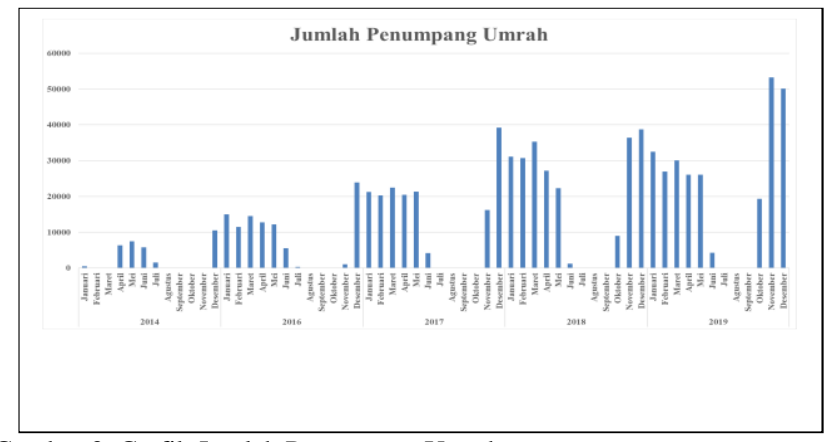

Gambar 3. Grafik Jumlah Penumpang Umrah.

Peramalah jumlah penumpang guna mengantisipasi jumlah penumpang yang tinggi pada tahun rencana, digunakan metode permalan time series dari tahun 2019 - 2024.

\section{B. Perencanaan Terminal Penumpang Umrah}

Perencanaan fasilitas terminal penumpang menggunakan standar berdasarkan SNI 03-7046-2004 dan SKEP/77/VI/2005 [5][6].

Analisis nilai LOS [4] guna mengetahui kapasitas pelayanan suatu fasilitas terminal penumpang umrah.

\section{Hasil dan Kesimpulan}

Hasil perencanaan terminal penumpang umrah berupa desain layout sesuai hasil dari analisis data.

\section{HASIL DAN PEMBAHASAN}

\section{A. Pergerakan Penumpang}

Pola keberangkatan penumpang umrah diketahui untuk mengetahui sistem pemrosesan penumpang umrah pada Bandar Udara Internasional Juanda dapat dilihat secara skematis pada Gambar 2.

Berdasarkan data sekunder yang dipeoleh dari PT Angkasa Pura I (Persero), volume pergerakan penumpang umrah di Bandar Udara Internasional Juanda pada tahun 2014 - 2019 mengalami trend yang semakin meningkat.

Dari Gambar 3, grafik data jumlah penumpang dapat dilihat bahwa pergerakan penumpang umrah di Bandar Udara Internasional Juanda secara umum mengalami peningkatan setiap tahunnya.

\section{B. Forecasting Jumlah Penumpang}

Untuk mengetahui perkiraan jumlah penumpang pada masa yang akan datang, perlu adanya forecasting jumlah penumpang
Tabel 2.

Data Jumlah Penumpang Umrah

\begin{tabular}{|c|c|c|c|c|c|c|}
\hline \multirow{2}{*}{ Bulan } & \multicolumn{6}{|c|}{ Tahun } \\
\hline & 2014 & 2015 & 2016 & 2017 & 2018 & 2019 \\
\hline Mei & 7490 & 10977 & 12197 & 21380 & 22295 & 26069 \\
\hline Juni & 5762 & 5774 & 5577 & 4181 & 1212 & 4273 \\
\hline Juli & 1512 & 1238 & 327 & & & \\
\hline Agustus & 43 & & & & & \\
\hline September & & & & & & \\
\hline Oktober & & & & & 8981 & 19358 \\
\hline November & & & 1069 & 16232 & 36393 & 53222 \\
\hline Desember & 10540 & 10482 & 23912 & 39250 & 38737 & 50133 \\
\hline Total & 32173 & 79055 & 96734 & 165470 & 232012 & 268626 \\
\hline
\end{tabular}

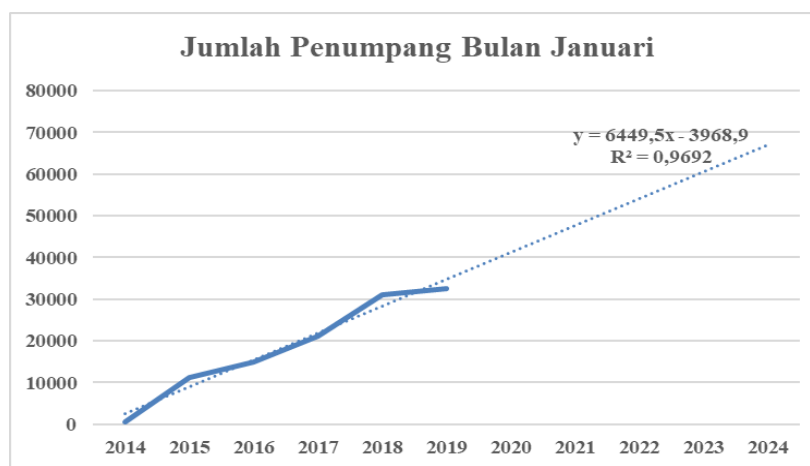

Gambar 4. Jumlah Penumpang Umrah Bulan Januari.

guna mengetahui kebutuhan luas pada masa mendatang. Metode yang digunakan dalam tugas akhir ini adalah analisis data jumlah penumpang umrah pada tiap bulan dalam kurun waktu tahun 2014 - 2019. Contoh analisis per bulan Januari dapat dilihat pada Gambar 5.

Hasil analisis data jumlah penumpang umrah hingga 5 tahun ke depan dapat dilihat pada Tabel 3.

\section{Perhitungan Peak Hour Penumpang Umrah}

Dengan menggunakan persentase nilai TPHP yang dikeluarkan oleh FAA, dapat dihitung jumlah penumpang peak hour pada tahun rencana. Namun karena jumlah penumpang umrah bersifat rombongan, diasumsikan persentase TPHP digunakan yang terbesar agar hasil penumpang peak hour nya besar. Contoh perhitungan peak hour berdasarkan persentase TPHP seperti berikut:

Penumpang tahun $2020=338549 \rightarrow$ TPHP $=0,12 \%$

Peak hour penumpang unrah $=338549 \times 0,12 \%=407$

Hasil perhitungan peak hour penumpang umrah dapat dilihat pada Tabel 4.

\section{Perhitungan Peak Hour Penumpang Domestik}

Untuk mengetahui jumlah peak hour penumpang domestik, menggunakan jadwal penerbangan domestik yang beririsan dengan penerbangan umrah. Didapat tanggal 23 Desember 30 Desember 2019. Peak hour tertinggi penerbangan umrah pada tanggal 23 Desember sebanyak 1710 penumpang, maka dianalisis jumlah peak hour pada penerbangan domestik pada tanggal 23 Desember 2019. Setelah didapat jadwal penerbangan beserta pax per pesawat (asumsi jumlah penumpang fully booked satu pesawat), jumlah penumpang didistribusikan dengan distribusi pola kedatangan penumpang berdasarkan IATA. Didapat jumlah peak hour penerbangan domestik 60 penumpang. 
Tabel 6.

Rekap Data Jumlah Penumpang Umrah

\begin{tabular}{cc}
\hline \hline Tahun & Jumlah Penumpang \\
\hline 2014 & 32173 \\
2015 & 79055 \\
2016 & 96734 \\
2017 & 165470 \\
2018 & 232015 \\
2019 & 268626 \\
2020 & 338549 \\
2021 & 399273 \\
2022 & 459996 \\
2023 & 520719 \\
2024 & 581806 \\
\hline \hline
\end{tabular}

Tabel 7.

Rekap Jumlah Peak Hour Penumpang Umrah

\begin{tabular}{cccc}
\hline \hline Tahun & Jumlah Penumpang & \%TPHP & $\begin{array}{c}\text { Penumpang peak } \\
\text { hour }\end{array}$ \\
\hline 2020 & 338549 & 0,12 & 407 \\
2021 & 399273 & 0,12 & 480 \\
2022 & 459996 & 0,12 & 552 \\
2023 & 520719 & 0,12 & 625 \\
2024 & 581806 & 0,12 & 699 \\
\hline \hline
\end{tabular}

Tabel 8.

Rekap Jumlah Peak Hour Penumpang Domestik

\begin{tabular}{cc}
\hline \hline Tahun & Peak Hour Domestik \\
\hline 2020 & 60 \\
2021 & 64 \\
2022 & 68 \\
2023 & 71 \\
2024 & 75 \\
\hline \hline
\end{tabular}

Untuk mengetahui jumlah peak hour pada tahun rencana, dihitung dengan pendekatan angka PDRB Kota Surabaya. Jumlah penumpang peak hour dikalikan dengan perbandingan PDRB tahun rencana dengan PDRB tahun 2019 untuk mengetahui jumlah peak hour pada tahun rencana. Hasil perhitungan peak hour domestik dapat dilihat pada Tabel 5.

Kemudian untuk perhitungan kebutuhan luasan terminal khusus penumpang umrah pada fasilitas yang digunakan bersama, dijumlahkan peak hour penumpang umrah dan peak hour penumpang domestik. Hasil perhitungan peak hour gabungan dapat dilihat pada Tabel 6 .

\section{E. Perhitungan Luasan Terminal}

Luasan kebutuhan terminal penumpang umrah Bandar Udara Internasional Juanda pada tahun 2020 - 2024 dihitung dengan menggunakan standar SNI 03-7046-2004 dan SKEP/77/VI/2005 [5][6].

Perhitungan kebutuhan luasan terminal penumpang di Bandar Udara Internasional Juanda dilakukan 2 skenario karena masih memungkinkan adanya irisan antara penumpang umrah dan penumpang domestik yang menggunakan fasilitas secara bersamaan.

Dari hasil perhitungan skenario 1 yang hanya menggunakan peak hour penumpang umrah sejumlah 699 penumpang, didapat kebutuhan luas terminal penumpang umrah adalah $14825,135 \mathrm{~m}^{2}$. Sedangkan untuk perhitungan skenario 2 dengan menjumlahkan peak hour penumpang domestik dan peak hour penumpang umrah dengan total 774 penumpang, didapat kebutuhan luas terminal penumpang umrah adalah $15694,14 \mathrm{~m}^{2}$.
Tabel 3.

Rekap Jumlah Peak Hour Gabungan

\begin{tabular}{cccc}
\hline \hline Tahun & $\begin{array}{c}\text { Peak Hour } \\
\text { Domestik }\end{array}$ & Peak Hour Umrah & $\begin{array}{c}\text { Peak Hour } \\
\text { Gabungan }\end{array}$ \\
\hline 2020 & 60 & 407 & 467 \\
2021 & 64 & 480 & 544 \\
2022 & 68 & 552 & 620 \\
2023 & 71 & 625 & 696 \\
2024 & 75 & 699 & 774 \\
\hline \hline
\end{tabular}

Tabel 4.

Hasil Perhitungan Luas Terminal Penumpang Umrah Perhitungan Pertama

\begin{tabular}{ccccc}
\hline \hline Tahun & $\begin{array}{c}\text { Jumlah } \\
\text { Penumpang }\end{array}$ & $\begin{array}{c}\text { Luas Terminal } \\
\text { Keberangkatan } \\
\left(\mathrm{m}^{2}\right)\end{array}$ & $\begin{array}{c}\text { Luas } \\
\text { Terminal } \\
\text { Kedatangan } \\
\left(\mathrm{m}^{2}\right)\end{array}$ & Total $\left(\mathrm{m}^{2}\right)$ \\
\hline 2020 & 338549 & 5678,555 & 2954 & 8632,555 \\
2021 & 399273 & 6695,2 & 3484 & 10179,2 \\
2022 & 459996 & 7699,48 & 4006 & 11705,48 \\
2023 & 520719 & 8717,125 & 4535 & 13252,125 \\
2024 & 581806 & 9752,135 & 5073 & 14825,135 \\
\hline \hline
\end{tabular}

Tabel 5.

$\underline{\text { Hasil Perhitungan Luas Terminal Penumpang Umrah Perhitungan Kedua }}$

\begin{tabular}{ccccc}
\hline \hline Tahun & $\begin{array}{c}\text { Penumpang } \\
\text { Peak Hour }\end{array}$ & $\begin{array}{c}\text { Luas Terminal } \\
\text { Keberangkatan } \\
\left(\mathrm{m}^{2}\right)\end{array}$ & $\begin{array}{c}\text { Luas } \\
\text { Terminal } \\
\text { Kedatangan } \\
\left(\mathrm{m}^{2}\right)\end{array}$ & Total $\left(\mathrm{m}^{2}\right)$ \\
\hline 2020 & 467 & 6027,555 & 3299 & 9326,555 \\
2021 & 544 & 7067,2 & 3854 & 10921,2 \\
2022 & 620 & 8096,48 & 4399 & 12495,48 \\
2023 & 696 & 9131,125 & 4946 & 14077,125 \\
2024 & 774 & 10187,135 & 5507 & 15694,135 \\
\hline \hline
\end{tabular}

Hasil perhitungan kebutuhan luas terminal penumpang umrah pada perhitungan skenario 1 dapat dilihat pada tabel 7 , sedangkan untuk perhitungan skenario 2 dapat dilihat pada Tabel 8.

\section{F. Nilai Level of Service Terminal Penumpang}

Analisis nilai level of service dilakukan pada fasilitas hall keberangkatan, passport area pada emigrasi, ruang tunggu keberangkatan, passport area pada imigrasi, dan hall kedatangan. Perhitungan dilakukan dengan menggunakan standar level of service dari IATA. Hasil analisis nilai LOS pada tahun rencana pada Tabel 9 dan Tabel 10.

\section{G. Desain Layout Terminal Penumpang Umrah}

Langkah terakhir adalah mendesain layout terminal penumpang umrah sesuai dengan peraturan dan literatur yang ada. Desain layout terminal penumpang umrah dilampiran, begitu pula layout eksisting terminal 1 Bandar Udara Internasional Juanda dilampirkan.

\section{H. Evaluasi Nilai LOS}

Hasil analisis nilai LOS yang masih dibawah standar dengan skor D/E (subdesign). Fasilitas yang belum bisa memenuhi standar level of service yaitu pada passport area saat emigrasi maupun imigrasi. Karena hasil perhitungan masih menunjukkan nilai LOS dengan skor D/E (sub design), maka direncanakan kebutuhan luas fasilitas tersebut adalah jumlah peak hour penumpang dikalikan dengan standar area per penumpang dengan skor C (optimum) yaitu $1,0 \mathrm{~m}^{2}-1,2 \mathrm{~m}^{2}$. 
Tabel 9.

Nilai LOS Fasilitas Terminal Penumpang Skenario 1

\begin{tabular}{|c|c|c|c|c|c|}
\hline \multirow{2}{*}{ Fasilitas } & \multicolumn{5}{|c|}{ Level of Service } \\
\hline & 2020 & 2021 & 2022 & 2023 & 2024 \\
\hline Hall Keberangkatan & Overdesign & Overdesign & Overdesign & Overdesign & Overdesign \\
\hline Passport Area Emigrasi & Subdesign & Subdesign & Subdesign & Subdesign & Subdesign \\
\hline $\begin{array}{l}\text { Ruang Tunggu } \\
\text { Keberangkatan }\end{array}$ & Overdesign & Overdesign & Overdesign & Overdesign & Overdesign \\
\hline Passport Area Imigrasi & Subdesign & Subdesign & Subdesign & Subdesign & Subdesign \\
\hline Hall Kedatangan & Overdesign & Overdesign & Overdesign & Overdesign & Overdesign \\
\hline
\end{tabular}

Tabel 10.

Nilai LOS Fasilitas Terminal Penumpang Skenario 2

\begin{tabular}{|c|c|c|c|c|c|}
\hline \multirow{2}{*}{ Fasilitas } & \multicolumn{5}{|c|}{ Level of Service } \\
\hline & 2020 & 2021 & 2022 & 2023 & 2024 \\
\hline Hall Keberangkatan & Overdesign & Overdesign & Overdesign & Overdesign & Overdesign \\
\hline Hall Kedatangan & Overdesign & Overdesign & Overdesign & Overdesign & Overdesign \\
\hline
\end{tabular}

hour penumpang sejumlah 774 penumpang, didapat kebutuhan

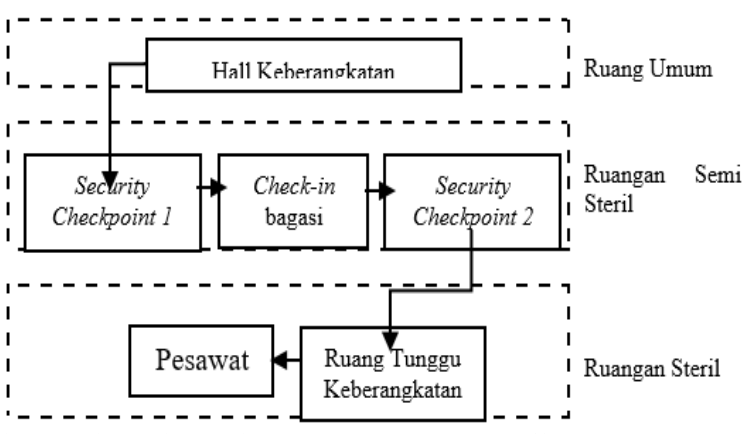

Gambar 5. Alur Keberangkatan Penumpang Domestik

Karena hasil kebutuhan luas berbeda dengan hasil perhitungan kebutuhan luas sebelum dianalisis nilai LOSnya, maka hasil kebutuhan total luas terminal penumpang umrah pada skenario 1 dan 2 pun berubah. Hasil perhitungan kebutuhan luas terminal penumpang umrah pada skenario 1 setelah luas fasilitas passport area emigrasi dan imigrasi adalah 16090,135 $\mathrm{m}^{2}$. Sedangkan kebutuhan luas terminal penumpang umrah pada skenario 2 adalah 16357,135 $\mathrm{m}^{2}$.

\section{KESIMPULAN DAN SARAN}

\section{A. Kesimpulan}

Berdasarkan hasil analisis yang telah dilakukan, maka diperoleh kesimpulan sebagai berikut:

\section{1) Pola Keberangkatan Penumpang Umrah}

Pola kedatangan penumpang umrah di Bandar Udara

Internasional Juanda dapat dilihat pada gambar 5.

2) Pertumbuhan Penumpang Umrah di Bandar Udara

Internasional Juanda

Berdasarkan hasil peramalan jumlah penumpang umrah dengan analisis tiap bulan dalam kurun waktu 2014 - 2019, didapat jumlah penumpang umrah di Bandar Udara Internasional Juanda pada tahun 2024 yaitu 581.806 penumpang.

\section{3) Kebutuhan Luas Terminal Penumpang Umrah}

Dari hasil perhitungan pertama yang hanya menggunakan peak hour penumpang umrah sejumlah 699 penumpang, didapat kebutuhan luas terminal penumpang umrah adalah $16090,135 \mathrm{~m}^{2}$. Sedangkan untuk perhitungan kedua dengan menambahkan peak hour penumpang domestik dengan peak luas terminal penumpang umrah adalah $16357,135 \mathrm{~m}^{2}$.

4) Desain Layout Terminal Penumpang

Desain layout terminal penumpang umrah yang efisien sesuai dengan peraturan dan literatur yang ada.

\section{B. Saran}

Metode peramalan yang digunakan dalam tugas akhir ini hanya menggunakan time series forecasting yang dimana hanya variabel waktu saja yang dipertimbangkan dalam peramalan jumlah penumpang. Maka untuk tugas akhir selanjutnya diharapkan lebih menilik tidak hanya satu variabel yang digunakan karena penumpang umrah tidak hanya terpengaruh akan waktu namun juga ekonomi karena masih belum bisa menjangkau segala strata sosial.

Pembangunan atau pengembangan bandara khususnya fasilitas darat berkaitan langsung dengan manusia dan semua aktivitasnya, hasil perhitungan menggunakan rumus menjadikan angka akan menjadi kaku dan perlu ditinjau juga dampak aplikatif pada kondisi eksisting. Diperlukan peninjauan berkala, karena semua yang berhubungan dengan manusia dan aktivitasnya bersifat dinamis dan abstrak, tidak terpaku pada angka yang dihasilkan oleh perhitungan teknis. Terkhususkan pula penumpang umrah yang sedang melaksanakan salah satu ibadah umat muslim, banyak budaya - budaya atau nilai - nilai agama yang perlu dipertimbangkan dalam perencanaan pengembangan terminal penumpang bandara.

\section{DAFTAR PUSTAKA}

[1] Badan Pusat Statistik, "Jumlah Penduduk Menurut Kabupaten/Kota dan Agama yang Dianut di Provinsi Jawa Timur," 2016. [Online]. Available: https://jatim.bps.go.id/dynamictable/2017/10/09/120/jumlah-pendudukmenurut-kabupaten-kota-dan-agama-yang-dianut-di-provinsi-jawatimur-2016.html.

[2] P. Semesta, "Semakin Nyaman, Para Jamaah Umroh Diberikan Fasilitas Lounge Umroh," 2017. [Online]. Available: https://airport.id/semakin-nyaman-para-jamaah-umroh-diberikanfasilitas-lounge-umroh/.

[3] Kementrian Agama, "Daftar Penyelenggara Perjalanan Ibadah Umrah," 2019. [Online]. Available: https://simpu.kemenag.go.id/home/travel.

[4] IATA, "LOS Concept," Montreal, Quebec, Canada, 2019.

[5] Badan Standarisasi Nasional Indonesia, "SNI 03-7046-2004 Terminal Penumpang Bandar Udara," 2004.

[6] D. J. P. Udara, Peraturan Direktur Jenderal Perhubungan Udara 
Nomor: SKEP/77/VI/2005 tentang Persyaratan Teknis Pengoperasian

Fasilitas Teknik Bandar Udara. 2005. 